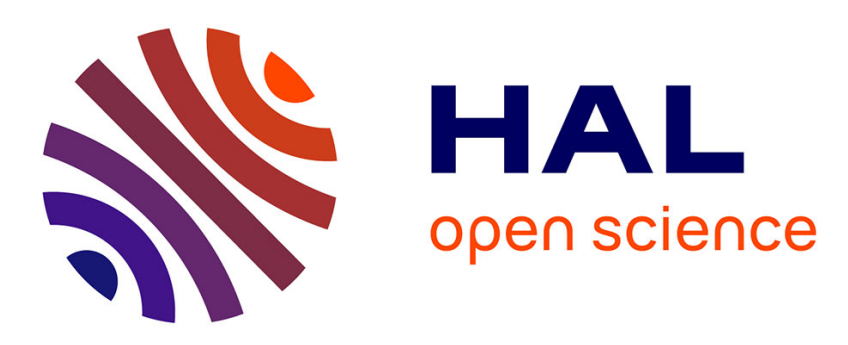

\title{
Impact of geometrical defects on bearing assemblies with integrated raceways in aeronautical gearboxes
}

Laurent Zamponi, Emmanuel Mermoz, Jean-Marc Linares, Jean-Michel Sprauel

\section{- To cite this version:}

Laurent Zamponi, Emmanuel Mermoz, Jean-Marc Linares, Jean-Michel Sprauel. Impact of geometrical defects on bearing assemblies with integrated raceways in aeronautical gearboxes. Mechanism and Machine Theory, 2009, 44 (6), pp.1108 - 1120. 10.1016/j.mechmachtheory.2008.10.005 . hal01426890

\section{HAL Id: hal-01426890 \\ https://hal-amu.archives-ouvertes.fr/hal-01426890}

Submitted on 5 Jan 2017

HAL is a multi-disciplinary open access archive for the deposit and dissemination of scientific research documents, whether they are published or not. The documents may come from teaching and research institutions in France or abroad, or from public or private research centers.
L'archive ouverte pluridisciplinaire HAL, est destinée au dépôt et à la diffusion de documents scientifiques de niveau recherche, publiés ou non, émanant des établissements d'enseignement et de recherche français ou étrangers, des laboratoires publics ou privés. 


\title{
Impact of geometrical defects on bearing assemblies with integrated raceways in aeronautical gearboxes
}

\author{
L. Zamponi ${ }^{\text {a }}$, E. Mermoz ${ }^{\text {a }}$,J.M. Linares ${ }^{\text {b,* }}$, J.M. Sprauel ${ }^{\text {b }}$ \\ ${ }^{a}$ EUROCOPTER, Aéroport Internationale Marseille Provence, 13725 Marignane, France \\ ${ }^{\mathrm{b}}$ ISM, UMR6233, Université de la Méditerranée/IUT, IUT d'Aix en Provence, Avenue Gaston Berger, 13625 Aix en Provence Cedex, France
}

\begin{abstract}
This paper presents a methodology to calculate the contact pressures on the rolling ele-ments and other significant parameters applicable to raceway bearings used in aeronauti-cal helicopter gearboxes. The mechanism is modelled by a hybrid method where the parts are decomposed in finite elements and the bearings are described by substitution features. This hybrid method accounts for the flexibility of the parts as well as geometrical defects. In this method, the contacts between rolling element and raceways are solved analytically. The Hertz contact theory is used to calculate the contact behaviour. The geometrical defects are included in the model thus changing the value of local displacements. Our paper shows the impact of the flexibility of the different mechanical parts and its geomet-rical defects, on the behaviour of the bearing raceways. Three most important conclusions are brought to the fore. First the load distribution in the bearing is modified by the flexibil-ity of the parts and the bearing raceways. Second, positioning defects in our assemblies have insignificant effect on the bearing service life. Third orientation defects increase the pressure in roller bearings and the balls orbital speed variation in ball bearings.
\end{abstract}

Keywords: Rolling bearings, Contact pressure, Kinematics, Hertz contact, Gearboxes, Design

\section{Introduction}

In aircraft industry, and in particular in manufacturing of helicopters, the search for maximum performance, whilst minimising on-board weight, is essential. A power transmission gearbox of $300 \mathrm{~kg}$ in weight can thus transmit several megawatts of mechanical power (Fig. 1).

In this type of helicopter power transmission gearbox, weight saving is achieved by reducing the number of parts and their thicknesses. For the rotational guidance of rolling elements, weight saving is achieved by replacing some classical bearing raceways by raceways integrated to the shafts or the housings and by reducing their thickness. A gear incorporating integrated raceway bearings is shown in Fig. 2. A part of this type saves weight, but is, on the other hand, more expensive to manufacture due to the complexity of the surfaces and its high geometrical quality.

In this paper, the impact of geometrical defects on the behaviour under load of integrated raceway bearings is studied. For that purpose, it is necessary to implement a complete model of the mechanism in order to account for: the stiffness of the parts, the external loads applied to the housing, the clearances in the bearings, the characteristics of the contacts, and the geometrical defects. The experience acquired by helicopter and bearing manufacturers has shown that the contact pressure between the rolling elements and the raceway is one of the criteria which affect the reliability of integrated raceways and their behaviour in-service. In the case of ball bearings, which are subjected to severe distortion of the raceway, the fatigue strength of the cage if also affected by the spreading of the rotational speed of the rolling elements. Indeed, during one

* Corresponding author. Tel.: +3304 429390 96; fax: +3304 42939070.

E-mail address: jean-marc.linares@univmed.fr (J.M. Linares). 


\section{Nomenclature}

a contact angle in UiZ plane

D rolling element diameter.

$\mathrm{dm}$ bearing pitch diameter

$\mathrm{F} \quad$ load applied to the bearing

$\mathrm{F}_{\mathrm{c}} \quad$ centrifugal force

J diametric clearance.

$\mathrm{K} \quad$ equivalent stiffness of substitution element

$\mathrm{K}_{\mathrm{h}} \quad$ contact stiffness between ball and raceways

L roller length.

M moment

Q contact load between rolling elements and raceways

$\mathrm{r} \quad$ raceway groove radius

$\mathrm{R} \quad$ rolling radius

$\mathrm{U}$ displacement between the inner and outer raceways in the vicinity of rolling element $\mathrm{i}$

$\mathrm{U}_{\mathrm{i}}, \mathrm{V}_{\mathrm{i}}, \mathrm{Z}$ Cartesian co-ordinates of ball $\mathrm{i}$, such that $\mathrm{w}_{\mathrm{i}}=\left(\mathrm{X}, \mathrm{U}_{\mathrm{i}}\right)=\left(\mathrm{Y}, \mathrm{V}_{\mathrm{i}}\right)$ in the XY plane

$V_{i} \quad$ orbital speed of centre of ball $i$

$\mathrm{V}_{\mathrm{A}}$ : tangential speed at point $\mathrm{A}$ of inner raceway

$\mathrm{V}_{\mathrm{B}} \quad$ tangential speed at point $\mathrm{B}$ of outer raceway

$\mathrm{X}, \mathrm{Y}, \mathrm{Z}$ Cartesian co-ordinates with Z-axis coincident with the bearing rotational axis, and the X-axis coincident with the radial load direction

d displacement at contact

$\mathrm{h}_{\mathrm{i}} \quad$ deflection angle between the inner and outer raceways in the vicinity of roller $\mathrm{i}$

$\mathrm{w}_{\mathrm{i}} \quad$ azimuth angle in $\mathrm{XY}$ plane

$\mathrm{X}$ angular velocity

\section{Subscripts}

a refers to axial direction

h refers to Hertz contact

i refers to rolling element $\mathrm{i}$

ir refers to inner raceway

or refers to outer raceway

$r$ refers to radial direction

$\mathrm{k} \quad$ refers to laminum position

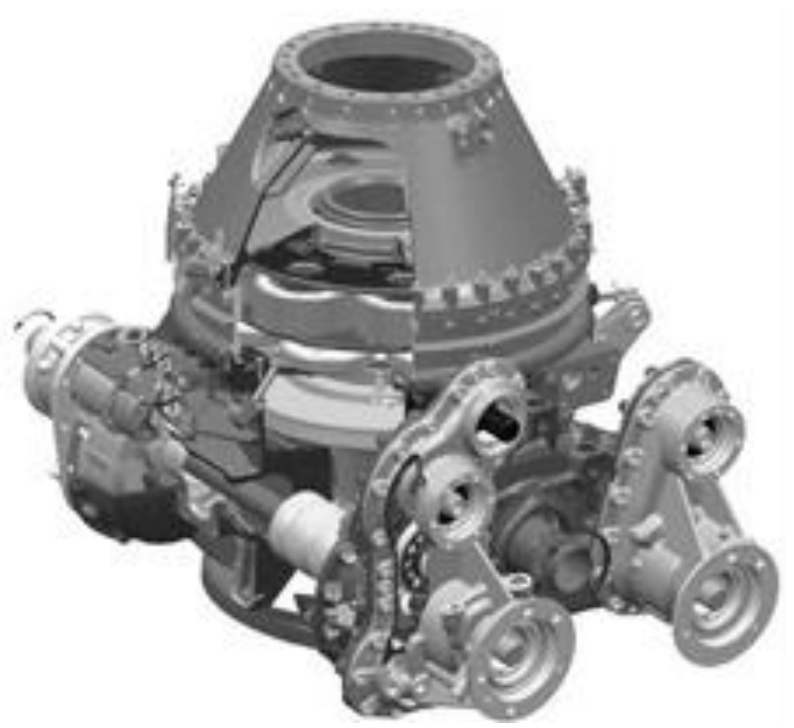

Fig. 1. View of a helicopter main gearbox. 


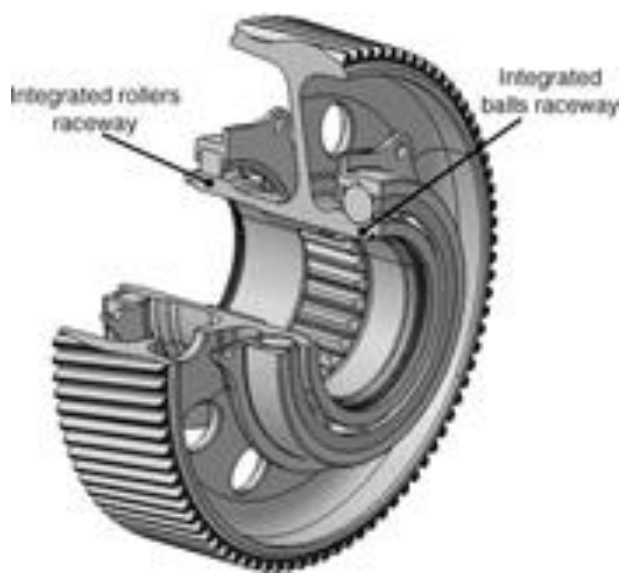

Fig. 2. Gear with integrated raceway bearings.

revolution of the bearing, if all the balls do not rotate at the speed of the cage, it may allow some balls to compensate for the cavity backlash (clearance between the cage and the ball). Such kinematical incompatibility may generate stresses in the cage, or sliding at the contact between the balls at weakest load and the raceways. In order to determine the pressures and angles (for ball bearings only) at the different contacts inside each bearing, it is essential to identify the local load distribution.

The behaviour of rolling bearings has been studied by many researchers in this last century. Professor Stribeck was one of the first scientists to publish a paper about loads within bearings. In his report [1], the author proposed studying the ball raceway contact by correlating the Hertz contact theory with several series of tests. Professor Stribeck obtained thus a relationship between the global radial load applied to the bearing and the highest load affecting the rolling elements. This work was the basis of ISO 76 standard [2] dedicated to the calculation of the basic static load. Lundberg and Palmgren [3] studied the fatigue behaviour of bearings, and thus developed a criterion which permits dimensioning the bearing. This work contributed to the establishment of ISO 281 standard [4]. A major advance in bearings behaviour knowledge was achieved in the middle of the 20th century through the work carried out by Jones [5] and Harris [6]. They aimed their study at the static and dynamic behaviour of bearings. The method proposed by Harris [6] is based on the assumption that displacements in a bearing are caused exclusively by the clearances and local deformation in the contact zones. This assumption is no longer valid if the bearing raceways are of low thickness, and even more so if the raceways are integrated with the shaft or the housing. It is the case for aircraft bearings. In the contribution by Harris and Jones [7], the classical Harris method was modified by introducing coefficients of flexibility which account for the deformation of the outer raceway of an idler gear. This raceway is incorporated in the idler gear immediately beneath the gear teeth. Zupan and Prebil [8] generalised this approach using the finite element method (FEM) to calculate the flexibility matrix of the structure in order to account for the overall deformation of the structure. The calculation of the flexibility matrix is however limited by the structure size because the inversion of the stiffness matrix requires long computing times. To overcome this problem, Hauswald and Houpert [9], used a matrix condensation technique (condensation of the stiffness matrix at the link nodes). Bourdon et al. [10] developed a hybrid model to account for the overall deformation, whereby the mechanism is meshed by classical elements and the rollers or balls of each bearing are replaced by non-linear elements attached to the two rings. In the work by Lovell et al. [11], the contact between a ball and two parallel plates, was modelled by FEM. The results were found close to those obtained by Hertz theory. Zhao [12] used 2D contact FEM, to calculate the load distribution in a bearing subjected to a radial load. Kang et al. [13] proposes a modification to Hertz contact law based on the modelling of the local contact by FEM. A similar approach was also used by Ludwik [14] to characterise the contact behaviour between the roller and the raceways. From these results, Ludwik modelled a slewing bearing by replacing the contacts with elements exhibiting non-linear behaviour.

According to the literature three methods are thus used: analytical, numerical and hybrid. It is essential for the mechanisms and for the type of bearings used in aeronautical applications, to account for the overall deformation of the parts. Indeed, for the studied mechanisms, about $30 \%$ of the relative displacement between the inner raceway and the outer raceway is due to the deformation of the parts (ovalisation of the raceways, deformation of the housing, etc.). On average, for integrated raceway bearings used in helicopters: $70 \%$ of the relative displacement between the inner and outer raceways is due to local contact deformation between the rolling elements / raceways, 20\% to deformation of the outer raceway and the housing, and 10\% to deformation of the shaft (integrated inner raceway). Our previous work [15,16], shows and details two methodologies which can be used to study integrated raceway bearings designed for helicopter gearboxes. A numerical method based on FEM, managing the contacts between the raceways and the rolling elements was studied. The meshing of the structure was also optimised in order to minimise the computing time. A hybrid method (analytical-numerical) was presented whereby the calculation were performed by the FEM. In this method, the contacts were replaced by substitution ele- 
ments. The overall objective of our work is now to propose a method for calculating the contact pressures and the contact angles on the integrated raceway bearing raceways including not only the deformations but also the geometric defects of the parts in the mechanism. This method must be incorporated in an industrial CAD software programme. In this article, we shall thus detail a hybrid method which can take into account geometric deformations. For that purpose a subassembly of a helicopter gearbox will be considered as case study. Then, the impact of geometric defects and deformations on the behaviour of the bearings and the other parts of the mechanism will be predicted. Concerning the bearings, we will focus on the variations of the contact pressures and rolling element orbital speeds.

\section{Hybrid numerical method}

\subsection{Principle and assumptions}

The modelling of the gearbox is achieved by FEM. The various parts of the gearbox are connected together through mechanical links. To simulate the behaviour of the mechanism, these links must thus be modelled. In the case of rolling element links, a model which accounts for the non-linear behaviour and the load distribution for each rolling element has been established. Contact conditions between the raceways and the rolling elements are replaced by substitution elements. The bearing is simply represented by its outer ring, these substitution elements, and the inner raceway integrated with the shaft. This modelling permits calculating the internal equilibrium of a bearing accounting for its internal geometry, the deformability of its contacts, the bearing raceways, the shaft and the housing.

The presented methodology does not account for the dynamic loads and the friction forces. In the context of the studied gearboxes, these can be neglected. The study of error introduced by dynamic load on the contact pressures and the orbital rotational speeds of the balls are shown in Section 2.4. The effects of lubrication are also neglected. In this article, the microgeometrical defects (surface roughness, indentation etc.) are not taken into account. Only the macro-geometrical defects (position, misalignment) are studied. Since damage of the mechanism is due to high cycle fatigue, the parts are only deformed elastically. Therefore, surface hardness does just have minor influence. The modelling of the mechanism is performed in the steady state condition (constant temperature). Thermal expansion is taken into account, in order to deduce the operating clearances of the bearings. The preloads are introduced by the boundary conditions in the FEM, either through the displacement, or through the loads on the bearings. The presented method has been integrated in the CATIA FEM. This enables us to maintain the link with the geometric model of the mechanism.

\subsection{Calculation procedure}

The resolution of the complete system by FEM and the analytical calculation of the contact behaviour are coupled in this calculation procedure. The modelling is performed using the CATIA V5 FEM. The different parts of de mechanism are meshed by linear tetrahedral elements. Complementary more precise simulations, using "SAMCEF" software demonstrated that this kind of elements is sufficient to study the behaviour of rolling bearing and the displacement field. At least 100,000 nodes are used for the modelling. The behaviour of materials is linear. The meshing of the link zone between raceway and substitution element is presented in Fig. 3. The substitution element is connected to the raceway through an area of about three square millimetres. The local deformation of the link zone is taking into account in the calculus.

The calculation procedure is detailed in the flow chart of the Fig. 4. At each iteration, the FEM calculation with its substitution elements is performed. The variables of the substitution elements (stiffness, orientation) are recalculated at each

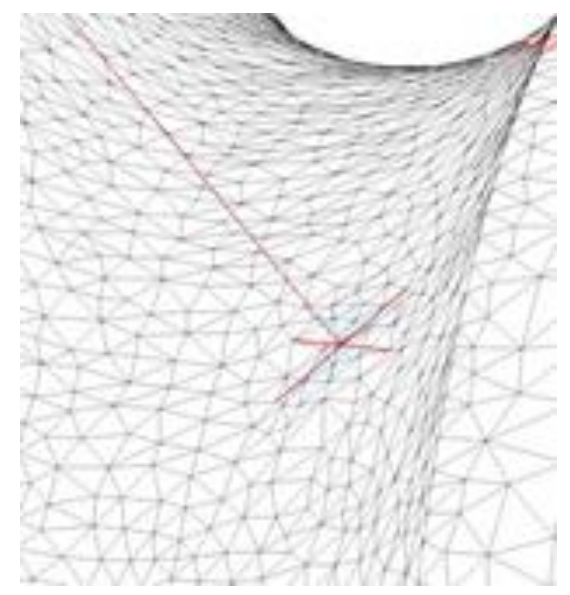

Fig. 3. Link zone between raceway and substitution element. 


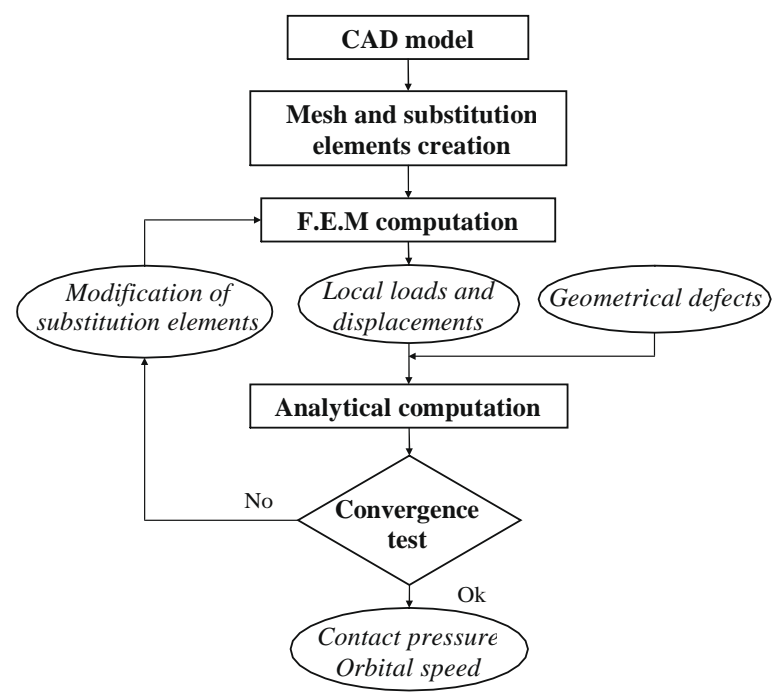

Fig. 4. Flow-chart of the hybrid method.

iteration. Convergence is assumed to be achieved when the variation of the stiffness of the substitution element is less than $0.1 \%$ between two successive steps. The analytical method for calculating the substitution elements is based on the Harris equations in [6]. The characteristics of the elements are controlled by a VB macro in CATIA V5. At each iteration, the input data of the analytical calculations are, for each substitution element, the relative displacements between attachment zones and sustained loads. Moreover, geometric defects of the bearings may be added. From these data, the local contact displacement and the orientation of the load may be determined. The analytical module and substitution elements are different if the bearing contains balls or rollers. In following paragraphs, the procedure for both ball and roller bearings will be detailed.

\subsubsection{Modelling of a ball bearing}

A ball bearing may be subjected to different types of loads: axial load, radial load and moment. Each ball is able to transmit a load. This load is orientated by the contact angle relative to the plane perpendicular to nominal rotational axis of the bearing Z. Fig. 5a shows loads applied to the ball bearing's inner ring.

The contact behaviour (balls-raceways) may be described by Hertz contact theory. Using Hertz theory, successively, for the contacts between the inner ring and the ball $i$, and between the ball $i$ and the outer ring, the following relationship can be deduced:

$$
\mathrm{Q}_{\mathrm{i}}{ }^{1 / 4} \mathrm{~K}_{\mathrm{h}} \partial \mathrm{d}_{\mathrm{i}} \mathrm{p}^{1 ; 5}
$$


Fig. 5. (a) Inner raceway loads of ball bearing; and (b) inner raceway loads of roller bearing. 




Fig. 6. (a) Ball bearing geometry; and (b) relative displacements in the section of ball i.

The overall contact stiffness $K_{h}$ depends on the internal geometry of the bearing, shown in Fig. 6a. Several articles [6,13,17] describe how to determine $\mathrm{K}_{\mathrm{h}}$.

The deformation $d_{i}$ and the angle of contact $a_{i}$ are dependent on the relative displacements between the inner and outer raceways in the section $\left(\mathrm{U}_{\mathrm{i}}, \mathrm{Z}\right)$ and on the internal geometry (c.f. Fig. 6b). The relationships linking these parameters are as follows:

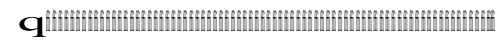

$$
\begin{aligned}
& d_{i}{ }^{1 / 4} \quad \partial r_{i} p r_{o} \ddot{y} D \ddot{y} J p U_{r i} p^{2} p \partial U_{a i} p d_{a} p^{2} \ddot{y} \partial r_{i} p r_{o} \ddot{y} D p \\
& \sin a_{i} 1 / 4 \text { q } \\
& \partial r_{i} p r_{o} \ddot{y} D \ddot{y} J U_{r i} p^{2} p U_{a i} p d_{a} p^{2}
\end{aligned}
$$

Relationships (1)-(3) describe the local behaviour of ball i in the bearing. In our model, the substitution elements replace the contacts between balls and raceways, as well as the balls. These substitution elements are orientated springs attached to the contact zones. This principle is illustrated in Fig. 7a.

The spring orientation is given by the angle of contact under load $\mathrm{a}_{\mathrm{i}}$ and the stiffness $\mathrm{K}_{\mathrm{i}}$ is given by the relationship below.

$$
K_{i} 1 / 4 \frac{Q_{i}}{\partial U_{a i} \sin a_{i} p U_{r i} \cos a_{i} p}
$$

At first iteration, the substitution elements get their initial orientation and stiffness. For subsequent iterations, the orientation and stiffness of each substitution element are then recalculated. The relative displacements $U_{\mathrm{ai}_{\mathrm{FE}}}$, $\mathrm{U}_{\mathrm{ri}_{\mathrm{FE}}}$ and the load $\mathrm{Q}_{\mathrm{i}}$ for each substitution element are obtained by the FEM calculations. To these relative displacements, the geometric defects of the bearing can be added in the following way:

$$
\begin{aligned}
& U_{\mathrm{ri}_{\mathrm{FEd}}} 1 / 4 U_{\mathrm{ri}_{\mathrm{FE}}} p U_{\mathrm{ri}_{\mathrm{d}}} \\
& U_{\mathrm{ai}_{\mathrm{FEd}}} 1 / 4 U_{\mathrm{ai}_{\mathrm{FE}}} p U_{\mathrm{ai}_{\mathrm{d}}}
\end{aligned}
$$

where

$$
\begin{aligned}
& U_{\mathrm{ri}_{\mathrm{d}}} 1 / 4 U_{\mathrm{r}_{1}} \cos \partial \mathrm{w}_{\mathrm{i}} p \mathrm{u}_{\mathrm{r}_{1}} \mathrm{p} \\
& U_{\mathrm{ai}_{\mathrm{d}}} 1 / 4 U_{\mathrm{ai}_{0}} p \mathrm{U}_{\mathrm{a}_{1}} \cos \partial \mathrm{w}_{\mathrm{i}} p u_{\mathrm{a}_{1}} p
\end{aligned}
$$

Eqs. (7) and (8) describe the position and orientation defects between the inner and outer raceways of the bearing. These defects are induced by the geometrical variations of the parts of the gear box (housing, shaft, casings etc.). For the moving
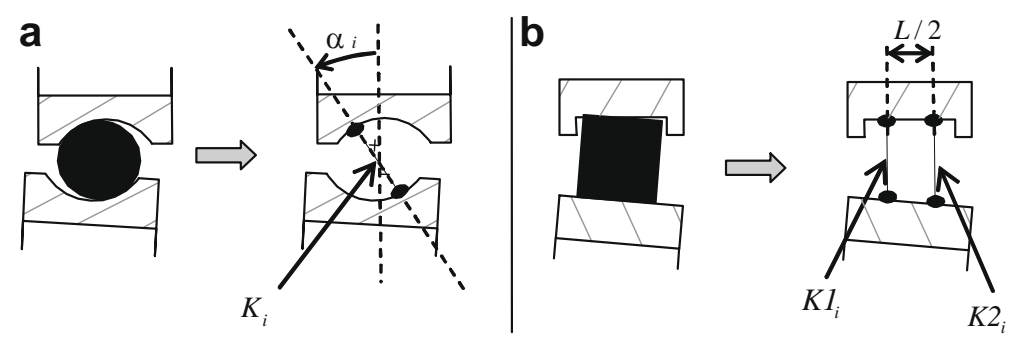

Fig. 7. (a) Substitution elements of ball bearing; and (b) substitution elements of roller bearing. 
parts, the calculation of these geometrical defects is very difficult. It is necessary to calculate the geometrical defect between the raceways for each position. In consequence, the localisation defects are simulated by the term $U_{r_{1}} \cos \partial w_{i} p u_{r_{1}} p$ for the radial offset between two raceways in polar coordinates. The term $U_{a_{i}}$ describes the axial offset between two raceways. The term $U_{a_{1}} \cos \partial w_{i} p u_{a_{1}} p$ simulates the orientation defects of the bearing (misalignment between two raceways) in polar coordinates. The new stiffness and orientation for each substitution element are obtained by calculating the deformation $\mathrm{d}_{\mathrm{i}}$ from the load $\mathrm{Q}_{\mathrm{i}}$ by reversing relationship (1). From the deformation $\mathrm{d}_{\mathrm{i}}$, the ratio between the radial displacement, $\mathrm{U}_{\mathrm{ri}_{\mathrm{FEd}}}$ and the axial displacement $U_{\mathrm{ai}_{\mathrm{FEd}}}$ obtained from relationships (5) and (6), and (2), the new displacement values ( $U_{\mathrm{ri}}$, $\left.U_{\mathrm{ai}}\right)$ may be derived. By injecting the values of displacements $\left(U_{r i}, U_{a i},\right)$ in relationships (2) and (4) the new values of stiffness and orientation are finally obtained. The iterative process terminates when the variation in stiffness between two consecutive iterations is less than $0.1 \%$.

\subsubsection{Modelling of a roller bearing}

A roller bearing may be subjected to different types of loads: radial and moment. Each roller is able to transmit a load and a moment along a contact line. Fig. $5 \mathrm{~b}$ shows the loads applied on the inner ring of a roller bearing. In the same way as for the contacts between the raceways and the balls in a ball bearing, contacts between the raceways and the rollers may be described by Hertz theory. However, for the model of the contact between two cylinders, Hertz theory does not provide a relationship linking the applied load to the deformation of the surfaces. Several authors have published relationships of the form of Eqs. (9) linking these two parameters.

$$
\mathrm{Q}_{\mathrm{i}} 1 / 4 \mathrm{~K}_{\mathrm{h}} \partial \mathrm{d}_{\mathrm{i}} \mathrm{p}^{\mathrm{n}}
$$

Houpert [17] has compared the different relationships and has proposed an analytical relationship inspired by the work performed by Tripp [18]. This new relationship introduces the contact length, the material coefficients and the equivalent radius of the cylinders in contact. Hoeprich and Zantapulos [19] studied by testing, the contact deformation of a cylinder between two planes. These tests showed that the equivalent radius has little influence on the contact stiffness. For our study, the relationship of Harris [6] is chosen because it does not account for the equivalent radius. The values of $K_{h}$ and $n$, for steel bearings are given by following relationship (10).

$$
\mathrm{K}_{\mathrm{h}} 1 / 4 \frac{\mathrm{L}^{8=9}}{2 ; 7510^{\ddot{y} 11}} ; \quad \mathrm{n} 1 / 410=9
$$

Relationship Eqs. (10) is not sufficient to describe the contact behaviour between the roller and the raceways. This type of contact can transmit both a load and a moment. For such configuration, the method proposed by Harris [6] is used. The cylinder/cylinder contact is divided into slices of width $\mathrm{w}$ as described in Fig. 8.

For each section, there is a deformation $\mathrm{d}_{\mathrm{ki}}$ and an associated load $\mathrm{Q}_{\mathrm{ki}}$. These two parameters are linked by the relationship (11). The sum of the loads $Q_{k i}$ per slice provides the full load $Q_{i}$ applied to roller $i$; the sum of the products of the load $Q_{k i}$ by the distance to the centre of contact gives the full moment applied to roller i.

$$
\mathrm{Q}_{\mathrm{ki}} 1 / 4 \frac{\mathrm{w}}{2: 7510^{\ddot{\mathrm{y}} 11} \mathrm{~L}^{1=9} \partial \mathrm{d}_{\mathrm{k} 1} \mathrm{p}^{10=9}}
$$

The deformation $\mathrm{d}_{\mathrm{ki}}$ is linked to the relative displacement between the raceways at roller $\mathrm{i}$ in the section ( $\left.\mathrm{U}_{\mathrm{i}}, \mathrm{Z}\right)$ by relationship Eq. (13). The profile correction of the roller at the edges may be taken into account by the term $C_{k}$. This term is detailed in [6] for radius edged rollers.

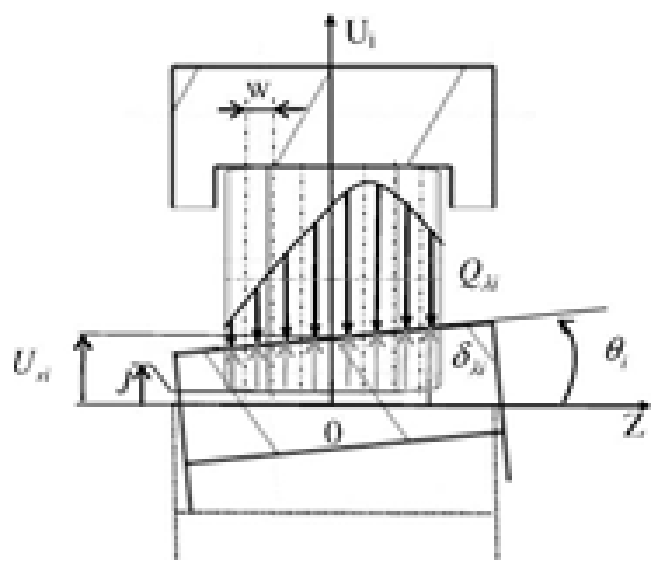

Fig. 8. Description of roller bearing contact. 


$$
\mathrm{d}_{\mathrm{ki}}{ }^{1 / 4} \mathrm{U}_{\mathrm{ri}} \ddot{\mathrm{y}} \mathrm{J} \mathrm{p}{ }_{2}^{1} \mathrm{kwh}_{\mathrm{i}} \ddot{\mathrm{y}} \mathrm{C}_{\mathrm{k}}
$$

Relationships(9)-(12) describe the local behaviour of the contacts at roller i. In our model, the substitution elements replace the contacts between the rollers and the raceways, and the rollers. These substitution elements are two springs of stiffness $\mathrm{K} 1_{\mathrm{i}}$ and $\mathrm{K} 2_{\mathrm{i}}$ symmetrically positioned on the contact line. Fig. $7 \mathrm{~b}$ describes this principle. At the first iteration of the FEM calculation, the substitution elements get their initial stiffness. For the subsequent iterations the stiffness of each substitution element is recalculated. The relative displacements $\mathrm{U} 1_{\mathrm{ri}}, \mathrm{U} 2_{\mathrm{ri}}$ and the loads $\mathrm{Q} 1_{\mathrm{i}}, \mathrm{Q} 2_{\mathrm{i}}$ for each substitution element $\mathrm{i}$ have been obtained by the FEM calculation (c.f. Fig. 9b).

The geometrical defects can be added to the relative displacements $\mathrm{U} 1_{\mathrm{ri}}, \mathrm{U} 2_{\mathrm{ri}}$. These defects are introduced using the same method as for the ball bearing, using relationships (5) and (7) with relative displacements $\mathrm{U} 1_{\text {ri }}$, $\mathrm{U} 2_{\mathrm{ri}}$. The deformation $\mathrm{d}_{\mathrm{ki}}$ per section can be calculated from these new values of relative displacements. The load $Q_{i_{d}}$ and the moment $M_{i_{d}}$ transmitted by the contact of roller $i$ were thus obtained by using relationship (10). Subscript $d$ is then used to identify such data. The load $\mathrm{Q}_{\mathrm{i}_{\mathrm{e}}}$ and the moment $\mathrm{M}_{\mathrm{i}_{\mathrm{e}}}$ transmitted by the contact at roller i can also be derived from the two forces Q1 $1_{\mathrm{i}}$ and $\mathrm{Q} 2_{\mathrm{i}}$ calculated by FEM. Subscript e is used for these values. Two estimates of the load $Q_{i}$ and the moment $M_{i}$, have thus been obtained. The previous one is obtained from the displacements and the second from the loads. The correct value lies between these two estimated values. The average of loads $Q_{i_{e}}$ and $Q_{i_{d}}$ have been chosen for the load $Q_{i}$. The average of moments $M_{i_{e}}$ and $M_{i_{i}}$ have been chosen for the moment $\mathrm{M}_{\mathrm{i}}$. The displacement $\mathrm{U}_{\mathrm{ri}}$ and the rotation $\mathrm{h}_{\mathrm{i}}$ required to obtain these loads are calculated by using a Newton-Raphson method. The stiffness of the substitution elements is calculated using relationship Eq. (13). The iteration process terminates when the variation in stiffness between two iterations is less than $0.1 \%$.

$$
\mathrm{K} 1_{\mathrm{i}} 1 / 4 \frac{\mathrm{Q}_{\mathrm{i}} \mathbf{p}_{\mathrm{L}}^{4} \mathrm{M}_{\mathrm{i}}}{2 \mathrm{U}_{\mathrm{ri}} \ddot{\mathbf{y}}_{2}^{\mathrm{L}} \mathrm{h}_{\mathrm{i}}} ; \quad \mathrm{K} 2_{\mathrm{i}} 1 / 4 \frac{\mathrm{Q}_{\mathrm{i}} \ddot{\mathbf{y}}_{\mathrm{L}}^{4} \mathrm{M}_{\mathrm{i}}}{2 \mathrm{U}_{\mathrm{ri}} \mathbf{p}_{2}^{\mathrm{L}} \mathrm{h}_{\mathrm{i}}}
$$

\subsection{Processing of the results}

The load distribution of the rolling element of each bearing is obtained at the end of the calculation procedure. This data enables the estimation of parameters which provide information on the in-service behaviour of the bearings. In our case, the contact pressures and the orbital speeds of the rolling elements are studied. The pressures provide information on the inservice performance of the raceways and rolling elements. Speeds of the rolling elements provide information on the behaviour of the cage (loading of the cage by speed variation). The pressure fields are calculated by Hertz theory. For the balls, Hertzian point contact is assumed. The equivalent radius is calculated at the contact point, identified previously. For rollers, a Hertzian line contact per section is assumed. Refs. [6] or [17] describe, in detail, the calculation method for the pressures. For our study, the methods described in [6] are used. Speeds of the rolling elements were obtained by a kinematic study of the bearing under load. Fig. 10 describes the kinematics of a ball bearing under load.

Deformations are represented by symbol d, were the subscript specifies the part which is subject to the deformation. The second subscript indicates the nature of the deformation: s for structure deformation, and h for Hertz contact deformation. In the structure deformation $\mathrm{d}$, the component in the radial direction is considered. The axial component is already covered by the calculation of the angle under load. For the kinematic study, only certain defects are taken into account: dimension, positioning, orientation and shape defects. In our model, we have dissociated the dimensional and shape defects from the positioning and orientation defects. These last defects affect the equilibrium of the system (load distribution per bearing and per ball) and the contact angles. Dimension and shape defects modify, only, the contact geometry. The all geometrical defects are
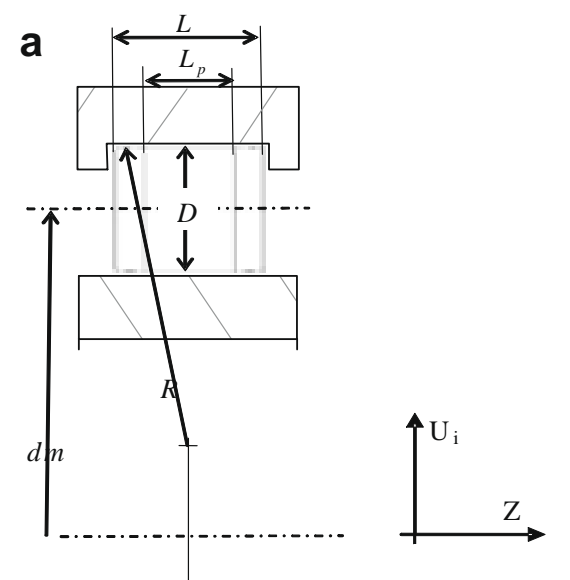

b

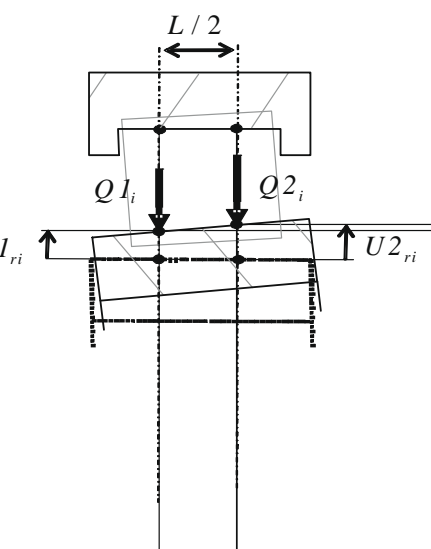

Fig. 9. (a) Roller bearing geometry; and (b) relative displacements in the section of roller $i$. 


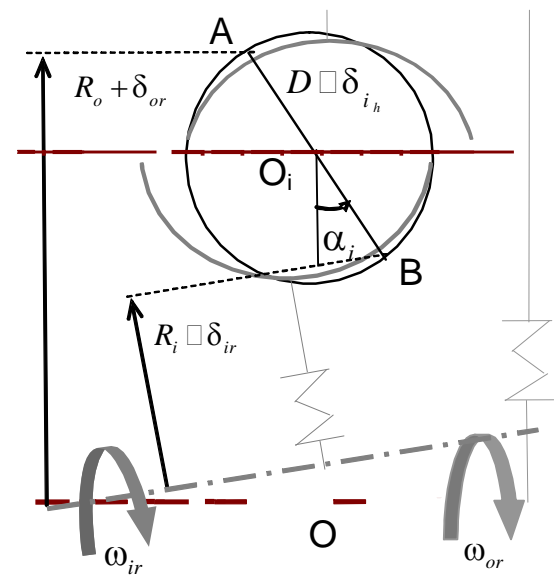

Fig. 10. Kinematic model of ball bearing under load

included into the FEM calculation which provides the deformations and the contact angles for each ball. At a subsequent step, dimension and shape defects are added which modify the radii values of the contact $R_{i}$ and $R_{\mathrm{o}}$. These radii can thus be written as

$$
\begin{aligned}
& \mathrm{R}_{\mathrm{i}}{ }^{1 / 4}{ }_{2}^{1 \ddot{y}} \mathrm{dmpd_{i_{0 } }} \ddot{\mathrm{y}} \mathrm{D}_{\mathrm{i}} \cos \mathrm{a}_{\mathrm{i}} \\
& \mathrm{R}_{\mathrm{o}}{ }^{1 / 4}{ }_{2}^{1} \mathrm{ym}_{\mathrm{y}} \mathrm{dr}_{\mathrm{r}_{0}} \mathrm{pD}_{\mathrm{i}} \cos \mathrm{a}_{\mathrm{i}}
\end{aligned}
$$

Eqs. (14) and (15) are written in the particular angular position of the moving part. In relationships (14) and (15), the term $\mathrm{d}_{\mathrm{xx}_{0}}$ represents the difference between the real diameter and the nominal diameter at the contact point for the inner and outer raceways. Variable $\mathrm{D}_{\mathrm{i}}$ represents the real diameter of the ball in the position $\mathrm{i}$. The rolling conditions without slip at A and $B$ provide the speeds of ball i relative to the fixed datum at those points:

$$
\begin{aligned}
& V_{B} 1 / 4 \partial R_{i} \ddot{y} d_{i r} p x_{i r} \\
& V_{A} 1 / 4 \partial R_{o} p d_{o r} p x_{o r}
\end{aligned}
$$

where

$$
d_{i r} 1 / 4 d_{i r_{h}} \cos a_{i} p d_{i r_{s}} ; \quad d_{o r} 1 / 4 d_{\text {or }_{h}} \cos a_{i} p d_{o r_{s}}
$$

The orbital speed of the balls is obtained by calculating the average of these two speeds.

$$
V_{i} 1 / 4 \frac{1}{2} \frac{1}{\partial R_{i}} \ddot{y} d_{i r} p x_{i r} p \partial R_{o} p d_{o r} p x_{o r} \dot{S}
$$

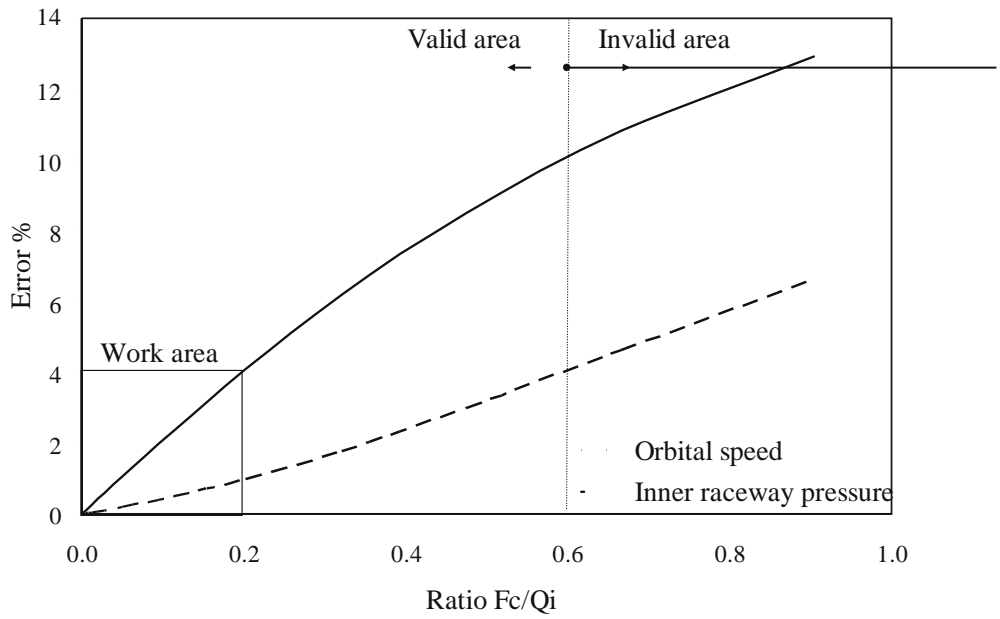

Fig. 11. Variation of orbital speed and contact pressure. 


\subsection{Error analysis of dynamic load effects}

The presented methodology does not account for the dynamic loads. This assumption is not usual because dynamic loads change balancing of the rolling elements and raceways. The error introduced by these hypotheses on the contact pressures and the orbital rotational speeds of the balls are shown in Fig. 11. These results are calculated according to the ratio between the centrifugal force $\left(\mathrm{F}_{\mathrm{i}}\right)$ and the load applied to each ball for a ball bearing $\left(\mathrm{Q}_{\mathrm{i}}\right)$. These plotted curves (Fig. 11) were obtained by using the analytical methods described by Professor Harris [6] for a ball bearing, respectively with and without dynamic loads. Concerning bearings in helicopter gearboxes, the ratio of the centrifugal force to the applied load is less than 0.2. The error introduced by neglecting the dynamic effects, is therefore quite acceptable: less than $1 \%$ for speeds and $4 \%$ for pressures. Additionally, this error introduces an overestimation of the contact pressures. This guarantees oversizing which ensures the mechanism safety. In conclusion, in the context of the studied gearboxes, the dynamic loads can be neglected.

\section{Results and discussions}

In previous paragraph, a hybrid method for modelling the links per bearing in a mechanism is presented. This method was validated in [15] and [16], by comparison with Harris method [6] for the case of a ball bearing with rigid raceways. This method is applied in a helicopter gearbox modelling. In this article, the results for subassembly of this gearbox are presented. The system studied is represented in Fig. 12.

The system consists of a housing which is mounted on the main housing, and containing a gear pair and four bearings. The pinion is guided to the housing via two integrated ball bearings. The wheel is guided to the housing via an integrated raceway ball bearing and an integrated raceway roller bearing. The average power transmitted by this gearbox is $150 \mathrm{~kW}$. The mechanical torque transmitted by the pinion is $300 \mathrm{Nm}$. The finite element model of the presented gearbox has 120,000 nodes. The various simulations presented in Figs. 13-17 highlight different phenomena like the impact of the flexibility and the geometric defects of the mechanism on the pressures and orbital speeds. For the geometric defects, the presented simulations were used to study only the position and orientation defects of the raceways. Our model is able to take other
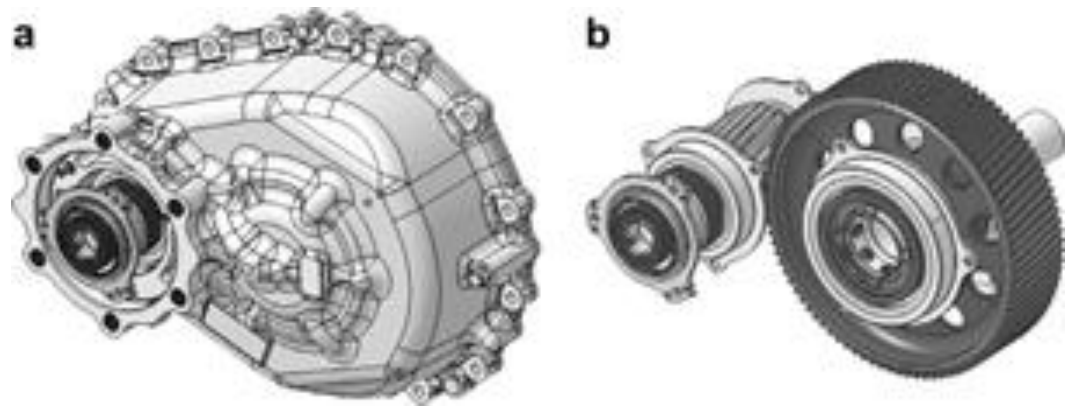

Fig. 12. (a) View of gearbox; and (b) view of bearings and gears.

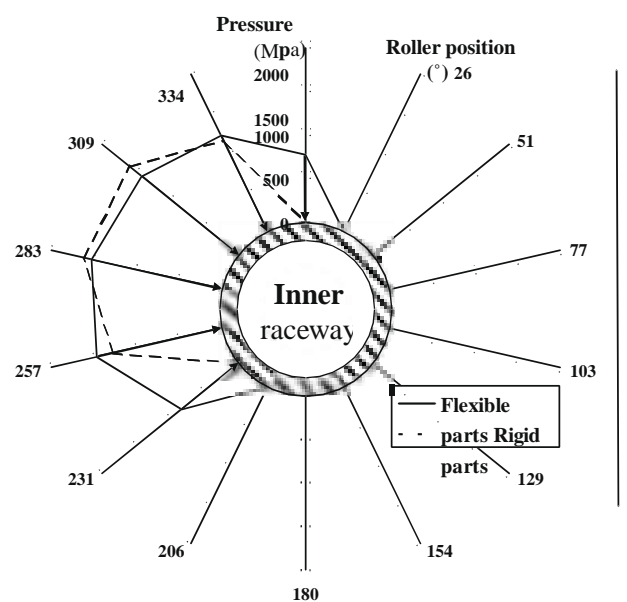

Roller bearing data

$$
\begin{gathered}
D m=80 \mathrm{~mm} \\
Z=14 \\
D=14 \mathrm{~mm} \\
L=14 \mathrm{~mm} \\
R=400 \mathrm{~mm} \\
J=0,045 \mathrm{~mm} \\
F_{r}=7600 \mathrm{~N} \\
M=17 \mathrm{Nm}
\end{gathered}
$$

Fig. 13. Pressure distribution for rigid and flexible parts in a roller bearing. 


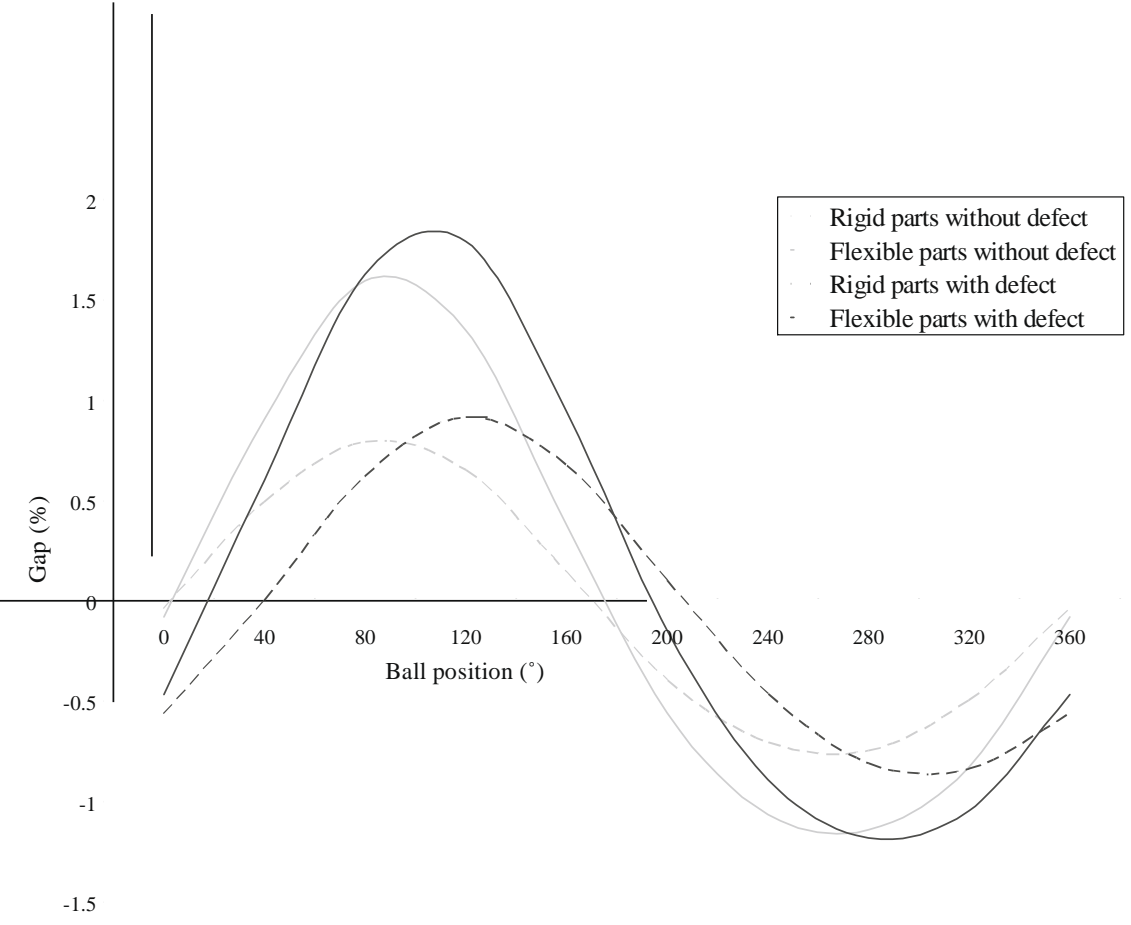

Fig. 14. Orbital speed gap for rigid parts with and without defects, and flexible parts with and without defect in a ball bearing.

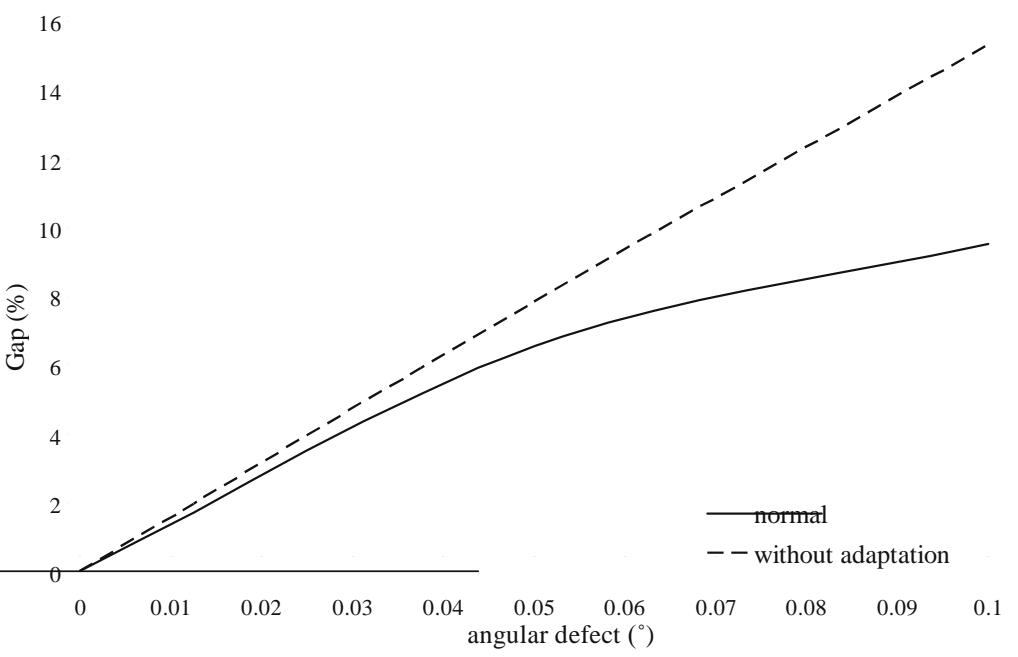

Fig. 15. Pressure gap evolution in relation to angular defects.

types of defects into account. The assemblies of bearings used exhibit a certain flexibility which afford them a low sensitivity to positioning defects of the raceways. However, this type of defect modifies the position of the shaft in the housing, which may generate overpressure or slippage problems for the gears. In simulations, only orientation defects are studied.

Fig. 13 shows the impact of the parts flexibility on the distribution of contact pressures on the bearing raceways. The presented example is a roller bearing whose characteristics are provided to the right of the Fig. 13. It is interesting to note the difference in pressure distribution on the inner raceway between the two performed simulations. In considering the deformability of the parts, leads to reduce the maximum pressures on the rolling elements by a few percents. The service life is calculated from the cumulative loads applied to the rolling elements, using Harris's method [6]. This method uses the value of each contact load. ISO 281 standard cannot be used for our problem because it treats only stiff raceways. In comparison to rigid parts, a 50\% increase in the service life is obtained for flexible parts. However, care is needed when interpreting this result; in the case of flexible parts, the service life calculation can be estimated with the sum of the stress due to contact and the stress due to the deformation of the raceways. This way will be studied in our future works.

Fig. 14 shows the effect of the deformation and the orientation defect on the orbital speed variation of the balls. The bearing modelled is a nine ball bearing subjected to axial and radial loads and a moment. All bearing balls are loaded. The graph shows a major difference between the flexible and the rigid models. The amplitude of the variations is $75 \%$ greater for the 
the direction of the orientation defect are added. According to this simulation, the pressure distribution in the ball bearing is relatively insensitive to orientation defects. The pressure of the most highly loaded zone does not vary. But in the least loaded zone, variations are significant: the pressure can be two times larger. This phenomenon reduces the bearing service life by a few percent. In this case, the service life reduces by $6 \%$ for the maximum orientation defect.

The orbital speed variation in a ball bearing is shown in Fig. 17 for different values of orientation defect. In this simulation, the defect was introduced in the most detrimental position. The amplitude of the speed variation is increased by the orientation defect. The increase was 50\% compared to its nominal value for a maximum orientation defect of $0.1^{\circ}$.

These simulations bring to the fore the impact of geometric defects and of the parts flexibility on the behaviour of integrated raceway bearings in helicopter gearboxes. In the studied cases, the parts flexibility permits a better pressure distribution and increases the bearing service life. Roller bearings are sensitive to orientation defects, but the mechanism flexibility reduces its overpressure effects. Ball bearings are better able to withstand orientation defects, but this last increase the orbital speed variations. The combination of the mechanism flexibility and an orientation defect may generate fatigue loads on the cage. Cage failure is a serious destruction mode. This failure leads to the crash of the mechanism. This type of simulation allows us to predict the service life of integrated raceway bearings. After experimentation, it may lead to dimensioning optimisation or to change the value of geometric specifications of integrated raceways.

\section{Conclusion}

The hybrid model presented enables us, on the one hand, to account for the global behaviour of bearings within a complete mechanism, and on the other hand, to determine precisely the local behaviour of the rolling elements. Additionally, the deformations and geometric defects of all the parts in the mechanism are included in this methodology. This proposal is, directly, embedded in the CATIA V5 environment, used in design. The presented simulations bring to the fore the effects of the flexibility and geometric defects of the parts on the bearing behaviour (deformation, contact pressure). The load distribution in the bearing is modified by the flexibility of the parts and the bearing raceways. The bearing service life is increased by this phenomenon. However, for ball bearings, the flexibility increases the balls orbital speed variation which can lead to failure of the cage. Positioning defects in our assemblies have insignificant effect on the bearing service life. Orientation defects increase the pressure in roller bearings and the balls orbital speed variation in ball bearings. In the future, we shall study the impact of shape defects on the bearing service life.

\section{References}

[1] R. Stribeck, Ball bearing for various loads, Trans. ASME 29 (1907) 420-463.

[2] ISO 76, Static load ratings.

[3] G. Lundberg, A. Palmgren, Dynamic capacity of rolling bearings, Acta Polytech. 7 Mech. Eng. Ser. 1 (3) (1947) 7-8.

[4] ISO 281, Dynamic load ratings and rating life.

[5] A.B. Jones, A general theory for elastically constrained ball and radial roller bearings under arbitrary load and speed conditions, ASME Trans. 82 (1960) $309-320$.

[6] T. Harris, Rolling Bearing Analysis, fourth ed., Wiley-Interscience, 2001.

[7] A.B. Jones, T. Harris, Analysis of a rolling element idler gear bearing having a deformable outer raceway structure, ASME Trans. J. Basic Eng. (1963) 273279.

[8] S. Zupan, I. Prebil, Carrying angle and carrying capacity of large single row ball bearing as a function of geometry parameters of the rolling contact and the supporting structure stiffness, Mech. Mach. Theor. 36 (2001) 1087-1103.

[9] T. Hauswald, L. Houpert, Numerical and experimental simulations of performances of bearing system, shaft and housing; account for global and local deformations, in: Presented at the SIA Seminar Fiabilité Experimentale, Proceeding of the Conference, 2000

[10] A. Bourdon, J. Rigal, D. Play, Static rolling bering model in a C.A.D. Environment for the study of complex mechanisms: Part I and II-rolling bearing model, ASME Trans. J. Tribol. 121 (1999) 205-214, 215-224.

[11] M.R. Lovel, M.M. Khonsari, R.D. Marangoni, A finite element analysis of the frictional forces between a cylindrical bearing element and MoS2 coated and uncoated surfaces, Wear 194 (1996) 60-70.

[12] H. Zhao, Analysis of load distribution within solid and hollow roller bearings, ASME Trans. J. Tribol. 120 (1998) 134-139.

[13] Y. Kang, P.C. Shen, C.C. Huang, S.S. Shyr, Y.P. Chang, A modification of the Jones-Harris method for deep-groove ball bearings, Tribol. Int. 39 (11) (2006) $1413-1420$.

[14] K. Ludwik, Modelling of rollers in calculation of slewing bearing with the use of finite elements, Mech. Mach. Theor. 41 (2006) $1359-1376$.

[15] L. Zamponi, E. Mermoz, J.M. Linares, Étude des méthodes de calcul des pressions de contact dans les roulements à pistes intégrées des boîtes de transmission aéronautiques, Méca. Indust. 8 (6) (2007) 567-576.

[16] L. Zamponi, E. Mermoz, J.M. Linares, Contact pressure calculation methodologies in aeronautic gearboxes in the CAD process, in: The Future of Product Development: Proceedings of the 17th CIRP Design Conference, 2007, pp. 451-462.

[17] L. Houpert, An engineering approach to Hertzian contact elasticity parts I and II, ASME J. Tribol. 123 (2001) 582-588, $589-594$.

[18] J.H. Tripp, Hertzian contact in two and three dimensions, NASA Technical Paper, 2473, 1985.

[19] M.R. Hoerprich, H. Zamtopulos, Line contact deformation: a cylinder between two flat plates, ASME J. Tribol. 103 (1981) $21-25$. 